\title{
PATIENT CENTEREDNESS IN HEALTH CARE: PERSPECTIVES FROM AN EMPIRICAL INVESTIGATION
}

\author{
REJIKUMAR G*, ARCHANA KS
}

\section{Department of Management, Amrita Vishwa Vidyapeetham, Kochi Campus, Kochi, Kerala. Email: drrejikumarg@gmail.com}

Received: 28 August 2017, Revised and Accepted: 05 May 2018

\section{ABSTRACT}

objectives: The objective of this study was to examine the formation of wellness perceptions and satisfaction from antecedents that explain various attributes regarding service quality perceptions about doctors by patients. The topic is of contemporary relevance as health-care firms are reengineering their competencies to deliver personalized health services to for unmatched experience to develop long-term relationships with patients.

Methods: Responses from 280 patients about service quality attributes of doctors, wellness perceptions, and their satisfaction are collected using a structured questionnaire. An exploratory factor analysis was performed using SPSS. 20 to identify significant dimensions of doctor's service quality. The theoretical model developed with these dimensions, wellness perceptions, and patient satisfaction was estimated using partial least square-based structural equation modeling approach to test hypotheses about linkages among these constructs.

Results: The dimension structure of doctor's service quality contained constructs such as "price affordability of medicines," "quality of diagnosis," "interaction quality of doctor," "appropriateness of tests prescribed," and "quality of usage prescriptions." These service quality dimensions of doctor significantly develop wellness perceptions and satisfaction among patients. Wellness perceptions act as a mediator in satisfaction development.

Conclusions: Patient satisfaction and wellness perceptions are of primary importance in improving service quality in health care and to remain competitive. The health-care firms should train their professionals to interact with the patients more efficiently by adhering to the philosophy of patient centeredness in their service process.

Key words: Price affordability of medicines, Quality of diagnosis, Interaction quality of doctor, Appropriateness of tests prescribed, Quality of usage prescriptions, Patient centeredness.

(C) 2018 The Authors. Published by Innovare Academic Sciences Pvt Ltd. This is an open access article under the CC BY license (http://creativecommons. org/licenses/by/4. 0/) DOI: http://dx.doi.org/10.22159/ajpcr.2018.v11i8.22262

\section{INTRODUCTION}

The Indian health-care sector is expected to register a compound annual growth rate of $22.9 \%$ during 2015-2020 to reach a market size of US\$ 280 billion [1]. The key contributors to this growth are rising income levels, improved health awareness, increased precedence of lifestyle diseases, and improved access to insurance [2]. India enjoys a competitive advantage in well-trained medical professionals. Treatment cost in India compared to peers in Asia and Western countries is less. Health-care services and pharmaceuticals contribute around $75 \%$ of the total health-care market. The Indian pharmaceutical companies through a series of mergers have enriched their competitiveness to become the favorable manufacturing hub for medicines in the world.

The health-care industry has undergone paradigm transitions in its structure. Now, the emphasis on customer orientation has become a prominent strategy for competitiveness and market success. In the pharmaceutical industry, technology adoptions and innovative drug research have resulted in the discovery of various generic medicines. The health-care protection has now extended to the majority of the population through exemplary policy initiatives of governments. Insurance in the health sector is fast penetrating to offer support to more customers. Personalized medicine and targeted therapies are some of the new trends in the market. The emerging trends are capable of altering the economic model of firms, and in the transition, the role of health-care professionals is going to be more critical.

The rationale behind the study

Markets are created and defined to cater to the growing needs of the customers. Marketers, over a period, try to reconcile with evolving complexities in the business environment and formulate their strategies for growth. In health care, the veto power of consumers in the selection of medicines is limited, since they are choosing drugs prescribed by a health-care professional. However, meeting their expectations of wellness, from the prescriptions, has due importance. These expectations relate to doctor's responsiveness, quality of treatment, fast relief from health problems, better service quality from hospitals, less risk from medications, etc. The concept of customer experience, though extensively studied in the service context, has no definite clue in health care. Customer experience is the aggregate of experiences perceived by the customer in his interaction with the service provider over the lifetime of the relationship. In health care, customer experience depends on health professional, the hospital environment, and the medicines prescribed for wellness. To ensure unmatched customer experience, the marketers should get right insights from patients about various attributes that satisfy them.

Awareness about attributes that create lasting experiences can help in devising strategies to accelerate prevailing growth trends. Assessing and estimating patient satisfaction and introducing timely initiatives to address issues are a significant step in the direction of service quality management in health care. This study proposes that the "doctor," being the most critical person in the health-care industry, plays a significant role in imparting patient satisfaction. Hence, the scope of this study is to examine service quality perceptions about doctors in developing wellness perceptions and satisfaction to patients. We expect that the information on doctor-related attributes, significant in satisfaction framework of patients, will help health-care professionals in designing tailor-made training programs for improving service quality in health care. Therefore, the objectives of this study are two: First, to explore 
the specific factors that determine service quality perceptions about doctors, and second, to critically analyze the relationship between so identified factors with wellness perceptions and satisfaction of patients.

\section{METHODS}

\section{Observations from previous studies}

The root of excellent patient experience relies mostly on patient satisfaction [3] received from doctors, hospitals, and medicines. Patients' satisfaction defines the extent to which general healthcare needs and condition-specific needs are met [4] on undergoing treatment. Assessing patient satisfaction is relevant, as satisfied patients express higher willingness to comply with treatment requirements [5], obey instructions of health-care professionals [6], and continue to remain with health-care service provider [7]. Furthermore, assessing patient satisfaction will benefit health-care service providers in multiple ways. The benefits include information on potential areas of service improvement [8]; clarity in drafting a patient-oriented service design [9]; ensuring quality care in health services [10]; in training health-care professionals [11]; and in new product development including personalized medicines [12].

Wellness perceptions can significantly alter the quality beliefs and satisfaction of patients. Wellness perceptions develop an equilibrium from the interplay among six dimensions of wellness such as physical, psychological, spiritual, social, emotional, and intellectual [13,14]. Disturbance in any of the dimensions may result in an imbalance and the ability restore the balance with the help of a health-care practitioner decides the satisfaction of patients. Wellness perceptions demonstrate a belief that imparts a sense of health regain. Wellness perceptions depend on factors such as health conditions of individuals, physical environment, genetic reasons, working conditions, and health- care system [15]. Wellness perceptions emerge from illness experience and quality of wellness programs [16]. Health is a passive component and wellness is the active component of a single concept [17] that captures overall wellbeingness of an individual.

Customer satisfaction is a primary principle in quality philosophies [18]. Satisfaction results in profitability, increased market share, employee and physician productivity, retention, and reduction of malpractice lawsuits [19]. In many occasions, non-clinical aspects of care than clinical elements develop better customer experience. Various attributes generate satisfaction among patients. Hospital Consumer Assessment of Healthcare Providers and Systems have identified nine critical areas as necessary in creating patient satisfaction. Three major areas in this list are related to quality communication by doctors, nurses, and about medicines. Two areas of importance are about quietness and cleanliness of hospital environment. Other areas are responsiveness of hospital staff, pain management, discharge information, and transition of care [20]. Quality of interactions with health-care team, quick responsiveness of staff, the hospital environment, and pain control practices [21] significantly develop satisfaction. Physician-patient communication [22], service environment, cultural integrations, and recovery speed [23] also merit consideration in the satisfaction framework.

Inadequate satisfaction can lead to switching over intentions in the presence of even a modest motivator, such as getting a better price and finding a more convenient location [24]. The ultimate patient satisfaction lies in creating patient value and in managing patient relationships [25]. Better value perceptions come from judgments comparing what accrued benefits (e.g. performance) to the acquisition costs (e.g., financial, psychological, and effort) [26]. Treatment experiences turn to be frustrating when faced with unexpected treatment cost, the occurrence of side effects from medication, confusing drug information, inconvenient pharmacy hours, lack of social/emotional support, unfriendly health-care professionals, difficult payment/reimbursement, and long wait times. Furthermore, patients' satisfaction as seen by the patient is critically important in formulating efficient to health-care delivery systems [27]. Hence, patientcentrism [28] becomes a core concept in the health-care industry, and in such a philosophy, doctors play a significant role. Therefore, patientcentric approaches in health care should start from doctors, and it is imperative that such aspects should have importance in the training of health-care professionals.

It emerges from above deliberations that the dynamics of patients' perception of quality are little different in health care compared to other service settings. Hence, to remain competitive, firms should identify problem areas and improve service standards that impart trust and value to patients. Implicitly or explicitly, there is a positive correlation between quality of service offered and attributes related to the hospital, health-care personnel, and medicines. These aspects help in attaining the desired outcome that meets patient expectations and satisfies them. Thus, a significant antecedent that develops patient satisfaction relates to doctors and their attitude toward patients. The quality of interactions with physicians and other factors related diagnosis and prescriptions improves wellness perception to result in satisfaction.

\section{Major constructs used in the study}

Quality equations in health care are outcomes of effective interactions between patient and various health-care professionals such as doctors, nurses, pharmacists, and other support personnel. Importance of effective communication with health-care professionals in ensuring satisfaction is well-documented [29-31]. Excellent and compassionate communication improves psychological health and makes patients feel relaxed [32]. A proper and humane approach, clear explanations about treatment, demonstration of proper concern, prompt resolution of requests, and appropriately addressing the patient queries make patient satisfied [33]. Information is highly relevant to satisfy patients. They expect proper information on treatment process, medicines, and its usage details. The clarity and appropriateness of the information provided in discharge summaries increase patient understanding about medications and make them satisfied [34]. All the above factors were one way or other linked to the quality of interactions.

Safety perceptions of the patients have a significant effect on their satisfaction [35]. Even though safety perceptions of patients are complicated to understand, a general belief is that patients expect safety in clinical procedures, prescription, hygiene, and no side effects of the medication. Drugs prescribed constitute a significant factor in patient satisfaction. The outcome of a treatment process depends on the quality of medicines and its' usage prescriptions. With the advent of many formulations under different brand names and generic equivalent of them, the patient's confusions have increased considerably. Quality and safety of generic medicines are causing an impact on patient satisfaction significantly. The assurance offered by doctors in this regard gives confidence to the patient about generic drugs [36]. Cost of medication forms a significant share of total medical expenses [37] and accounts for up to $80 \%$ of medical expenditure. Easy availability [38] and price affordability of medicines (PAoM) are therefore relevant factors that influence patient satisfaction. Patients usually believe that doctor knows about medicines more than pharmacists [39]. Therefore, patients evaluate the quality of a doctor regarding his knowledge toward drugs, his compassionate behavior, and diagnosing skills as more critical for wellness perceptions.

The above observations helped to conclude on the main constructs for this study. They are the service quality of doctor, wellness, and satisfaction as perceived by patients. The theoretical perspective behind this study postulates that patient satisfaction is an outcome of perceived doctor's service quality mediated through wellness perceptions of the patients.

\section{Operationalization of constructs}

This study analyzed the relationships between constructs that represent beliefs and attitudes of patients. These beliefs are abstract and not directly measurable. Hence, previous studies were reviewed to identify 
appropriate indicators that will measure the constructs. Two forms of relationships such as indicators assumed as reflections of the latent construct and indicators account for the formation of a construct [40] are explained in the literature. Thus, the indicators can be reflective or formative, and the choice depends on the research objectives, theoretical justification, and experimental conditions [41]. An expert panel reviewed and shortlisted 17 items that explain service quality of the doctor about his interaction, diagnosis, prescriptions, and drug recommendations. Wellness perception scale was designed as a multiple item one in which three items were adapted from perceived wellness scale [13] and two items as suggested by experts. Similarly, patient satisfaction was measured using five contextually relevant reflective items proposed by experts. A formative conceptualization was ideal for wellness perceptions since correlations among indicators are not expected [42]. Indicators of doctor quality were reflective and assumed to have a multidimensional structure. The final conceptualization of the theory that explains patient satisfaction was finalized after identifying the dimension/factor structure of doctor's service quality.

\section{Research methodology}

The study was descriptive and used cross-sectional data from a sample size of 280 respondents collected using a structured questionnaire. The questionnaire had two parts. The first part included questions to elicit details related to the demographic profile of the patients such as name, age, gender, qualification, annual income. The second part comprised 27 questions related to all indicators used for measurement. The questions were as closed-ended questions, where the respondents need to make their response on a 5-point Likert scale, varying from "strongly disagree" to "strongly agree." The selection of respondents was on a random basis by approaching them at different hospitals in Kochi, Kerala. To obtain natural responses reflecting personal experience of respondents, all the questions started with "doctors I consulted."
Factor structure of service quality of doctor

Exploratory factor analysis (EFA) using SPSS. 20 produced KaiserMeyer-Olkin measure of sampling adequacy of 0.783 , which is above the recommended value of 0.6 , and Bartlett's test of sphericity was significant $\left(\chi^{2}(136)=1060.58, \mathrm{p}<0.05\right)$. Also, the communalities were all above 0.3 , confirming that each item shared some common variance with other items. All these observations justified the use of factor analysis. Principle component analysis is more useful when the primary purpose is to identify the distinct factors that comprise doctor's service quality. The estimation using varimax rotation produced a five-factor solution, which explained $66 \%$ of the variance. The factor names suggested are capable of representing the common theme contained in each combination of items extracted after EFA. Table 1 presents the relevant output from EFA's and descriptive statistics of all items used in the study.

\section{The naming of the factors}

The first factor contained items that revealed capabilities of the doctor in recommending medicines that are affordable. Hence, this factor was named as "PAoM" to define the ability of the doctor to identify and recommend brands of drugs which are price affordable to patients. The second factor explained diagnostic capabilities of the physician in finding exact reasons for illness and performing satisfactory examinations. Hence, named as "quality of diagnosis" (QoD). The third factor depicted the quality of communication between patient and doctor. This factor is named as "interaction quality of doctor" (IQoD). The fourth factor explained patients' perceptions about the appropriateness of tests prescribed (AoTP) for diagnosing illness. Hence, this factor is named as "AoTP." The last factor represented the "quality of usage prescriptions" (QoUP) that a doctor gives in writing to patients to understand the mode and schedule of medication.

Table 1: Item descriptive and factor loadings

\begin{tabular}{|c|c|c|c|c|c|c|}
\hline \multirow{2}{*}{$\begin{array}{l}\text { Quality attributes of doctor (reflective) } \\
\text { Doctor related attributes }\end{array}$} & \multirow{2}{*}{$\begin{array}{l}\text { Mean } \pm \text { SD } \\
\text { PAoM }\end{array}$} & \multicolumn{5}{|c|}{ Factors and loadings } \\
\hline & & QoD & IQoD & АоTP & QoUP & \\
\hline Carefully listened to my problems & $3.31 \pm 0.915$ & & 0.669 & & & \\
\hline Clarified all my concerns & $3.11 \pm 1.035$ & & 0.745 & & & \\
\hline Offered proper advice for fast recovery & $3.42 \pm 0.83$ & & 0.6 & & & \\
\hline Found out reasons for my illness correctly & $3.83 \pm 1.089$ & 0.665 & & & & \\
\hline Correct tests required to find reasons for my illness & $3.86 \pm 0.925$ & 0.701 & & & & \\
\hline Spent enough time for diagnosing my illness & $4.3 \pm 0.913$ & 0.748 & & & & \\
\hline Explained clearly about illness & $3.59 \pm 0.816$ & & 0.69 & & & \\
\hline Prescribed medicines which I could afford & $4.06 \pm 0.974$ & 0.809 & & & & \\
\hline Were aware of affordable brands of medicines & $3.89 \pm 0.99$ & 0.817 & & & & \\
\hline $\begin{array}{l}\text { Doctors I consulted gave confidence to patients to use } \\
\text { affordable brands }\end{array}$ & $3.87 \pm 1.034$ & 0.71 & & & & \\
\hline Usage prescriptions were easy to understand & $4.26 \pm 0.737$ & & & & & 0.782 \\
\hline Written usage prescriptions were clear and legible & $3.99 \pm 0.769$ & & & & & 0.748 \\
\hline Explained clearly why prescribed tests are required & $4.03 \pm 0.71$ & & & 0.745 & & \\
\hline Explains test results and cleared all doubts & $3.94 \pm 0.783$ & & & 0.777 & & \\
\hline Wellness perceptions (formative) & & Loadings & & & & \\
\hline Emotional relief & $4.2 \pm 0.858$ & 0.294 & & & & \\
\hline Physical relief & $3.93 \pm 0.796$ & 0.321 & & & & \\
\hline Psychological support & $3.73 \pm 0.823$ & 0.35 & & & & \\
\hline Confidence inducing & $4.08 \pm 0.806$ & 0.322 & & & & \\
\hline Relief to near ones & $3.7 \pm 0.894$ & 0.287 & & & & \\
\hline \multicolumn{7}{|l|}{ Patient satisfaction (reflective) } \\
\hline Doctors attitude was as expected & $3.01 \pm 0.984$ & 0.699 & & & & \\
\hline Satisfied with diagnosis & $3.94 \pm 0.703$ & 0.684 & & & & \\
\hline Satisfied with overall outcome of treatment & $3.93 \pm 0.794$ & 0.697 & & & & \\
\hline $\begin{array}{l}\text { Satisfied with formalities in booking } \\
\text { consultation (dropped) }\end{array}$ & $2.24 \pm 0.707$ & & & & & \\
\hline Professional approach & $3.63 \pm 0.979$ & 0.308 & & & & \\
\hline
\end{tabular}

SD: Standard deviation, PAoM: Price affordability of medicines, QoD: Quality of diagnosis, IQoD: Interaction quality of doctor, AoTP: Appropriateness of tests prescribed, QoUP: Quality of usage prescriptions 
The confirmatory phase of the factor analysis was performed in the next stage to examine the validity/reliability statistics of above-identified dimensions.

\section{Examination of validity and reliability of factor structure}

To confirm generalization of the factor structure identified in EFA, a confirmatory factor analysis (CFA) using AMOS 22 was used. CFA requires data to have adequate multivariate normality. Even though normality deviations noticed, such deviations were non-problematic since absolute skewness and kurtosis values at Univariate level were $<3$ and 10 [43]. However, to moderate the effect of multivariate non-normality, the maximum likelihood estimation, which is relatively robust against departures from multivariate normality even in a small manner $[44,45]$, was applied with Bollen-Stine bootstrap procedure in 500 samples. A CFA allows researchers to evaluate the degree to which their measurements are consistent with actual data produced by respondents using the scale. The reported fit indices and parameter estimates confirmed that the model truly represents data and each item is relevant in measuring the variable meant. The threshold limits of fit criteria adopted were normed Chi-square (CMIN/df) $<3$, standardized root mean square residual (SRMR) $<0.08$, goodness-offit index $(\mathrm{GFI})>0.9$, comparative fit index (CFI) $>0.9$, root mean square error of approximation (RMSEA) $<0.08$, Pclose $>0.05$, and Hoetler at $0.05>200$ [43]. Fig. 1 illustrates confirmed factor structure of all attributes used to measure doctor quality.

The model emerged as one with adequate fit criteria $(\mathrm{CMIN} / \mathrm{df}=1.54$, SRMR $=0.048, \mathrm{GFI}=0.93, \mathrm{CFI}=0.944, \mathrm{RMSEA}=0.044$, Pclose $=0.74$, and Hoetler at $0.05=228$ ). The standardized loadings of items ranged from 0.517 to 0.852 with $t>1.96$ to confirm item significance [45] and suitability in measuring the construct [45]. The validity examination of the constructs using Microsoft Excel-based validity concerns toolkit developed by Prof. Gakingston could not find any validity challenges as composite reliability $(\mathrm{CR}>0.7)$ and average variance extracted $(A V E>0.5)$ was above threshold values. Further, maximum shared variance was less than AVE to confirm discriminant validity.

\section{Research model}

The dimensions of doctor's service quality act as antecedents to wellness perceptions and satisfaction of patients. On this logic, the following theoretical model (Fig. 2) is conceptualized and proposed for the estimation to examine the linkages prevailing among the constructs. The various hypotheses proposed for estimating the strength of relationships are as follows:

$\mathrm{H}_{1}$ : Various dimensions of doctor's quality such as PAoM, QoD, IQoD, AoTP, and QoUP have significant relation with wellness perceptions of patients.

$\mathrm{H}_{2}$ : Various dimensions of doctor's quality such as PAoM, QoD, IQoD, AoTP, and QoUP have significant relation with patient satisfaction.

$\mathrm{H}_{3}$ : Wellness perceptions significantly develop satisfaction to patients.

$\mathrm{H}_{4}$ : Wellness perceptions significantly mediate the formation of satisfaction from PAoM, QoD, IQoD, AoTP, and QoUP.

\section{RESULTS}

\section{Respondent's demographic characteristics}

The sample had $42 \%$ of male and $58 \%$ of female. The age range was from 22 to over 68. Dominant respondents (33.2\%) were of the age group 31-45 followed by the age group of $46-60(26.3 \%)$. Majority of the respondents fall in the income bracket of Rs 25,000-50,000 (36.5\%) followed by income bracket of Rs 50,000-75,000 (32\%). Similarly, the majority of the respondents were graduates (46.8\%) followed by postgraduates $(22.6 \%)$.

\section{Model estimation}

A structural equation modeling approach using partial least square (PLS)-based software Warp PLS 5.0 estimated the model. WarpPLS 5.0 can handle both reflective and formative constructs, and it produces robust estimates even when the data deviates from normality and sample size adequacy requirements. After verifying the quality of data for missing values, zero variance, and rank problems using the preprocessing algorithm, all indicators were standardized. The estimation algorithm for measurement models and structural model was PLS regression and Warp2 basic algorithm, respectively. PLS algorithm performs successive iterations till the loadings become stable [46]. Many relationships involving behavioral variables are nonlinear [47] model. In determining " $p$ " values that verify the significance of paths in the model, bootstrapping resampling method that maximizes the variance explained by the latent variable indicators [42] is used. Fig. 3 illustrates the estimated model with all path coefficients and corresponding $P$ values.

\section{Reliability and validity assessment}

WarpPLS 5.0 produces various fit measures for evaluating the overall quality of the model. The average path coefficient (APC), average R-squared, and average-adjusted R-squared (AARS) should be statistically significant $(\mathrm{p}<0.05)$; average block variance inflation factor (AVIF) and average full collinearity factor (AFVIF) should be $<3.3$, to confirm adequate fit. The Tanenhaus goodness-of-fit (GoF)

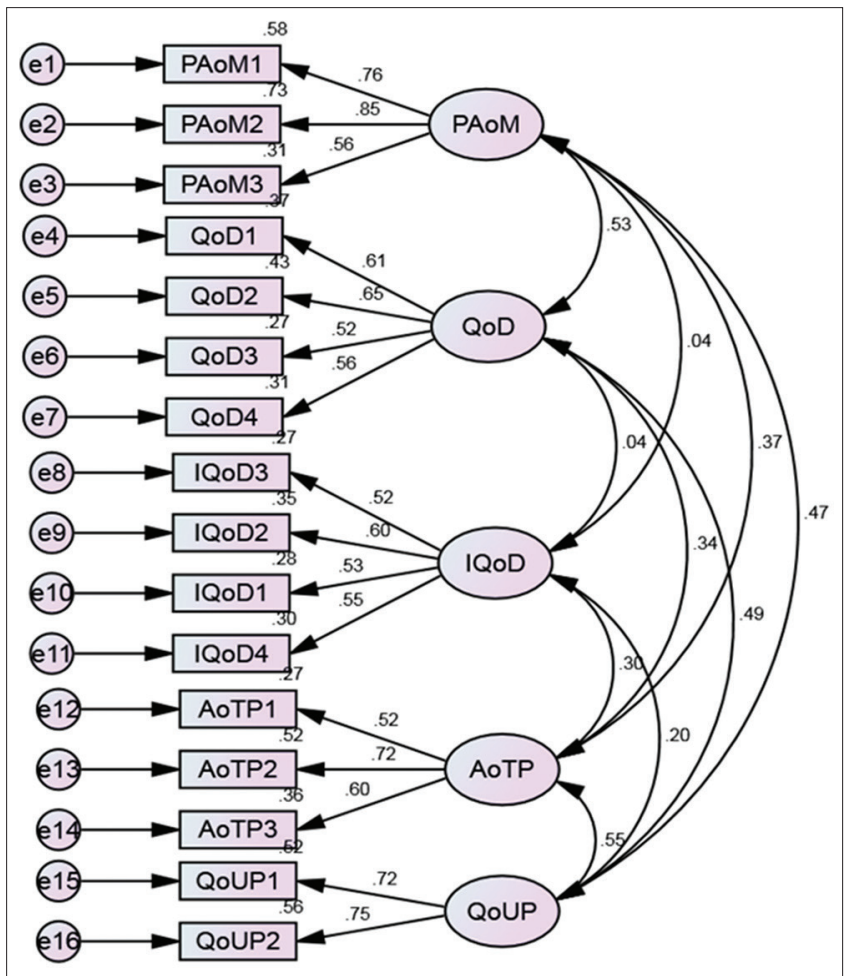

Fig. 1: Confirmatory model of doctor's service quality attributes

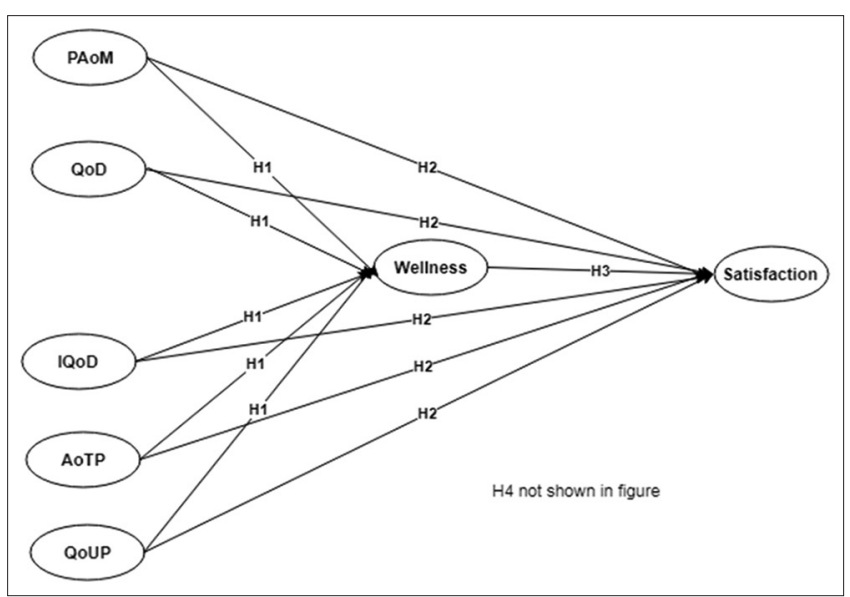

Fig. 2: Research model 
that measures a model's explanatory power [40] should be $>0.36$ to establish large fit [48]. Item relevance in measurement can be ensured when all reflective indicators have loadings more than 0.5 with $\mathrm{p}<0.05$ (Hair et al., 1998) and cross-loadings are $<0.3$. Similarly, all formative indicators should have weights that are statistically significant at $\mathrm{p}<0.05$ and variance inflation factor $<2.5$ to rule out that indicators measure the same facet of a formative construct [43]. The above observations also confirmed the existence of convergent validity in measurement. Positive values of R-squared, as well as Q-squared, establish predictive validity. CR and Cronbach's alpha values above 0.7 for reflective constructs and variance inflation factor <3.3 [40] for formative constructs confirmed adequate reliability in measurements. AVE above 0.5 concludes discriminant validity [49] of constructs. Full collinearity VIFs of 3.3 or lower suggest the absence of multicollinearity and common method bias [42]. The square root of AVE of all constructs needs to be more than any of the correlations involved with a particular latent variable to reaffirm discriminant validity [49].

The model emerged with significant fit values $(\mathrm{APC}=0.151$; $\mathrm{ARS}=0.291$; AARS $=0.277 ; \mathrm{GoF}=0.396 ; \mathrm{AVIF}=<3.3 ; \mathrm{AFVIF}=<3.3$ ). Values of $\mathrm{CR}$, Cronbach's alpha, AVE, and VIF had values above threshold levels. The $\mathrm{R}$-squared, as well as Q-squared, was positive. All the observations

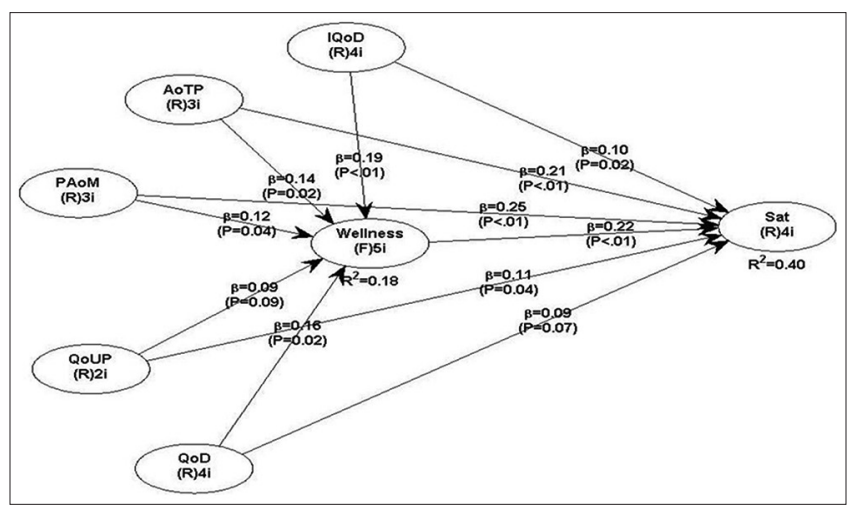

Fig. 3: Estimated research model regarding reliability and validity had acceptable levels to conclude on causality assumptions.

\section{Results of hypothesis tested}

Table 2 presents the path estimates and results of first three hypotheses tested. All the hypotheses proposed about the direct relationship between variables were found significant at $\mathrm{p}<0.05$ except for two paths between QoUP to wellness and QoD to satisfaction. These paths were significance only at 0.1 levels. A comparison of indirect effects, direct effects, and total effects of different paths in the model offered insights about mediating role of wellness perceptions.

Table 3 presents the indirect effects, direct effects, and total effects as reported from the output of WarpPLS 5.0. The direct effect was found significantly lower than the total effects on satisfaction, and further, the indirect effects were significant at either 0.05 or 0.1 level. These observations supported the mediating effect of wellness perceptions. Since direct effect was only dipping, the effect is of partial mediation [50]. Thus, hypothesis H4 was supported.

\section{DISCUSSIONS}

The major observations from this study are as follows: Service quality perceptions about doctor positively influence wellness perceptions and satisfaction of patients. The IQoD emerged as the most contributing factor of wellness perceptions $(\beta=0.19)$ followed by diagnosis skills $(\beta=0.16)$. Similarly, highest contributors of satisfaction are the prescription of affordable medicines $(\beta=0.24)$ and recommending appropriate diagnosis tests $(\beta=0.21)$. Highest indirect effect on satisfaction is from IQoDs $(\beta=0.04)$. Even though the causal power of antecedents differs in magnitude, all of them are contributing toward wellness perceptions and satisfaction.

The findings underline the observation that interactive consultations that offer clarity to patients make them feel more relaxed and satisfied. Any service is a co-creation process where service providers and the customers participate in true spirit [51]. A doctor through his confidence giving behavior ensures active participation of the patients. The willingness exhibited by patients to honestly express their issues and comply with the instructions of doctors improves the overall quality of

Table 2: Results of hypothesis testing

\begin{tabular}{lllll}
\hline Hypothesis & Path & $\boldsymbol{\beta}$ & $\mathbf{p}$ & Result \\
\hline $\mathrm{H}_{1}$ & PAoM to wellness & 0.118 & 0.043 & accepted at 0.05 level \\
& QoD to wellness & 0.163 & 0.015 & accepted at 0.05 level \\
& IQoD to wellness & 0.186 & $<0.001$ & accepted at 0.05 level \\
& AoTP to wellness & 0.135 & 0.019 & accepted at 0.05 level \\
& QoUP to wellness & 0.087 & 0.089 & accepted at 0.1 level \\
$\mathrm{H}_{2}$ & PAoM to satisfaction & 0.252 & $<0.001$ & accepted at 0.05 level \\
& QoD to satisfaction & 0.087 & 0.073 & accepted at 0.1 level \\
& IQoD to satisfaction & 0.104 & 0.024 & accepted at 0.05 level \\
& AoTP to satisfaction & 0.212 & $<0.001$ & accepted at 0.05 level \\
$\mathrm{H}_{3}$ & QoUP to satisfaction & 0.106 & 0.042 & accepted at 0.05 level \\
\hline & Wellness to satisfaction & 0.216 & $<0.001$ & accepted at 0.05 level \\
\hline
\end{tabular}

PAoM: Price affordability of medicines, QoD: Quality of diagnosis, IQoD: Interaction quality of doctor, AoTP: Appropriateness of tests prescribed, QoUP: Quality of usage prescriptions

Table 3: Testing of hypothesis related to mediation

\begin{tabular}{|c|c|c|c|c|c|c|}
\hline \multirow[t]{2}{*}{ Constructs } & \multicolumn{2}{|l|}{ Wellness } & \multicolumn{4}{|l|}{ Sat } \\
\hline & Satisfaction to wellness & Wellness to Sat & Direct effects & Indirect effects & Total effects & $p$ values of total effect \\
\hline PAoM & 0.118 & 0.216 & 0.252 & $0.026^{*}$ & 0.278 & $<0.01$ \\
\hline QoD & 0.163 & 0.216 & 0.087 & $0.035^{* *}$ & 0.122 & 0.02 \\
\hline IQoD & 0.186 & 0.216 & 0.104 & $0.04^{* *}$ & 0.144 & 0.004 \\
\hline АоTP & 0.135 & 0.216 & 0.212 & $0.019 * *$ & 0.241 & $<0.01$ \\
\hline QoUP & 0.087 & 0.216 & 0.106 & $0.029 *$ & 0.124 & 0.021 \\
\hline
\end{tabular}

*Significant at 0.1 level, ${ }^{* *}$ significant at 0.05 level. PAoM: Price affordability of medicines, QoD: Quality of diagnosis, IQoD: Interaction quality of doctor,

AoTP: Appropriateness of tests prescribed, QoUP: Quality of usage prescriptions 
treatment. Effective interaction with doctor imparts trust perceptions among patients about the procedures recommended. Effective ways of communicating with patients without disturbing their confidence level [52] are vital in the satisfaction framework. Most of the indicators classified under each dimension were showing loadings above 0.65 except the item referring to the quality of physical examinations. Furthermore, one item used in satisfaction measurement, "formalities related booking appointment with the doctor," failed to get adequate loading for inclusion in the model. Similarly, another item related to professional approach had very low loadings. These are areas of potential attention for improving satisfaction. The total effect of various antecedents significantly advances due to the mediating role of wellness feelings. Quality perceptions in medical service are more of intangible, and hence, a belief that the service provider is trying to offer relaxation to mind and body of the patient can increase satisfaction from quality dimensions.

The ability to offer excellent patient experience has evolved into a corecompetency concept to the service providers for sustained advantage in health care. The patient centeredness [53] that encompasses qualities of compassion, empathy, and responsiveness to the needs, values, and expressed preferences of the individual patients is prominent themes for the unmatched patient experience. Understanding the impact of above attributes of patient satisfaction is critical for devising policies for better performance of health-care firms [54]. Patient's perception of doctors' quality lies in many aspects. The doctor should understand the ways to achieve patient centeredness. Patients have clear expectations regarding the ideal role of physicians, and hence, their satisfaction to a great extent depends on traits of professional skill, communication skill, professional ethics, interpersonal skill, and personal characteristic displayed by a doctor. Therefore, health-care industry should try to enhance professional skills and communication attitudes of personnel to gain a competitive edge.

With the advent of the internet, customers have easy option to get information on various risks attached to medications. Right communication can therefore significantly develop trust among patients. High levels of competition and globalization of the pharmaceutical industry resulted in spreading of poor-quality medicines [55]. Now, patients are highly skeptic about the quality of drugs advised by doctors. Pharmaceutical representatives adopt many tactics to promote their products and physicians are motivated to involve in their marketing plan. Patient's perception of doctor's involvement in these activities adversely affects their credibility.

Equitable access to safe and affordable medicines is crucial to the health and well-being of people [56]. Affordability means something that can be afforded and believed to be within one's financial means. The patient should get a feeling that the medicines are reasonably priced, and they are getting the real value in return for what they pay. Doctors who prescribe readily available and affordable drugs are considered more trustworthy. The prescriptions written by the physician inform patients about the medications and their usage details. The prescriptions should be precise and readable for compliance. Doctors should prescribe medicines only when adequate knowledge of the patient's health is obtained and feel that the drugs or treatment suggested will serve the patient's needs [57]. Such sensible prescription practices are expected to enhance doctor's credibility and increase patient satisfaction.

The indicators used to measure service quality attributes of doctors in this study revealed that patients expect doctors to keep up the timings, behave cordially, and communicate with clarity. Competence, trustworthiness, and goodwill (caring) are identified to impart credibility feel about physicians [58]. The belief that a doctor genuinely cares for patient feelings gives satisfaction [59]. Patient compliance with prescriptions is better when they perceive doctor as credible and trustworthy [60]. Furthermore, credibility-enhancing cues in written medical messages enhance patients' confidence and compliance.

\section{Practical implications}

The emphasis on the quality of life is more evident in present-day individuals, and the demand for health care is increasing. To respond positively to this changing environment, health-care service providers should engage in organizational reengineering by improving internal quality from doctors and other touch points in the service process. Health-care sector needs to optimize their human resources regarding knowledge, skills, and attitude. Doctors should be adequately informed about the changes in the ecosystem and should be trained for implementing a professional interactive medical service encounter for patients. Given the mounting patient awareness, where information is readily available to every customer to make reviews and comparisons, a customer-oriented operational philosophy creates better value and enhances patient satisfaction to encourage revisits so that sustainability will not be at stake.

\section{CONCLUSIONS}

Ptient satisfaction is an individual's perception that delivers a direct opinion of the treatment received [61]. Many changes in the industry landscape create more challenges for management professionals in health care. The fierce competition and rising levels of patient expectations necessitate the need to convert every encounter a memorable experience to patients. The intangible nature of the service compels professionals to engage in service delivery that appeals to innate feelings of patients. Since patients significantly differ in their demographics, cultural background, and values, a standard approach to map their beliefs is difficult. The patient centeredness thus suffers a major setback even when such philosophies are propagated. Therefore, the doctor further becomes a central focus to showcase the patient orientation philosophy of the firm. The interaction effect and treatment effect on patients from the doctor can make the patient understand the value of the firm. To develop more personalized services, hospital administrators should try to identify different customer segments and align their service process to suit the needs of each segment. The scope of information technology may be utilized to develop platforms for higher interaction with health-care professionals.

\section{Limitations}

This research had many limitations. First, the scope of the study was limited to doctor-related factors in developing wellness perceptions and satisfaction. Other factors influencing patient satisfaction such as hospital environment, nature of the illness, and peer support are not considered. Second, a major concern exists on the extent of bias in responses due to the difference in demographic profiles of respondents. Third, the primary data collected are likely to be affected by defensiveness, distortions, sentiments, and other hidden behaviors of respondents since the questions were about confidential beliefs. Finally, the data were cross-sectional and thus may have only short-term validity as the factors considered are general and dynamic. Future research in this area should attempt to include hospital environment-related factors also into the framework of patient satisfaction

\section{CONFLICTS OF INTEREST}

All authors have none to declare.

\section{AUTHORS' CONTRIBUTION}

All the authors have contributed equally.

\section{REFERENCES}

1. Srinivasan V, Chandwani R. HRM innovations in rapid growth contexts: The healthcare sector in India. Int J Hum Res Manage 2014;25:1505-25.

2. Joumard I, Kumar A. Improving Health Outcomes and Health Care in India. Vol. 1184. OECD Economic Department Working Papers; 2015. p. 1-29.

3. Berkowitz EN. Essentials of Health Care Marketing. Sudbury, MA: Jones and Bartlett Publishers; 2016.

4. Asadi-Lari M, Tamburini M, Gray D. Patients' needs, satisfaction, and health related quality of life: Towards a comprehensive model. Health Qual Life Outcomes 2004;2:1-15.

5. Guldvog BJ. Can patient satisfaction improve health among patients with angina pectoris. Int J Qual Health Care 1999;11:233-40.

6. Donabedian A. Quality and cost: Choices and responsibilities. Inquiry 
1988;25:90-9.

7. Marquis MS, Davies AR, Ware JE Jr. Patient satisfaction and change in medical care provider: A longitudinal study. Med Care 1983;21:821-9.

8. Aharony L, Strasser S. Patient satisfaction: What we know about and what we still need to explore. Med Care Rev 1993;50:49-79.

9. Fottler MD, Ford RC, Roberts V, Ford EW. Creating a healing environment: The Importance of the service setting in the new consumeroriented healthcare system. J Health Care Manage 2000;45:91-106.

10. Jensen HI, Ammentorp J, Kofoed PE. User satisfaction is influenced by the interval between a health care service and the assessment of the service. Soc Sci Med 2010;70:1882-7.

11. Mayer TA, Cates RJ, Mastorovich MJ, Royalty DL. Emergency department patient satisfaction: Customer service training improves patient satisfaction and ratings of physician and nurse skill/practitioner response. J Health Care Manag 1998;43:427-40.

12. Lesko LJ. Personalized medicine: Elusive dream or imminent reality. Clin Pharmacol Ther 2007;81:807-16.

13. Adams T, Bezne, J, Garner L, Woodruff S. Construct validation of the perceived wellness survey. Am J Health Stud 1988;14:212-8.

14. Hatfield E, Cacioppo JT, Rapson RL. Emotional contagion. Curr Dir Psychol Sci 1993;2:96-9.

15. Bringsén $\AA$, Andersson HI, Ejlertsson G. Development and quality analysis of the Salutogenic Health Indicator Scale (SHIS). Scand J Public Health 2009;19:13-9.

16. Watt D, Verma S, Flynn L. Wellness programs: A review of the evidence. Can Med Assoc J 1998;158:224-30.

17. Reicherter EA, Greene R. Wellness and health promotion: Educational applications for older adults in the community. Top Geriatr Rehabil 2005;21:295-303.

18. Wicks AM, Roethlein CJ. A satisfaction-based definition of quality. J Bus Econ Stud 2009;15:82-97.

19. Riskind P, Fossey L, Brill K. Why measure patient satisfaction. J Med Pract Manage 2011;26:217-20.

20. Elliott MN, Cohea CW, Lehrman WG, Goldstein EH, Cleary PD, Giordano LA, et al. Accelerating improvement and narrowing gaps: Trends in patients' experiences with hospital care reflected in HCAHPS public reporting. Health Serv Res 2015;50:1850-67.

21. Kahn SA, Iannuzzi JC, Stassen NA, Bankey PE, Gestring M. Measuring satisfaction: Factors that drive hospital consumer assessment of healthcare providers and systems survey responses in a trauma and acute care surgery population. Am Surg 2015;81:537-43.

22. Schmocker RK, Stafford LM, Siy AB, Leverson GE, Winslow ER. Understanding the determinants of patient satisfaction with surgical care using the consumer assessment of healthcare providers and systems surgical care survey (S-CAHPS). Surgery 2015;158:1724-33.

23. Kupfer JM, Bond EU. Patient satisfaction and patient-centered care: Necessary but not equal. JAMA 2012;308:139-40.

24. Schneider B, Bowen DE. Understanding customer delight and outrage. Sloan Manage Rev 1999;41:35-46.

25. Strasser S, Aharony L, Greenberger D. The patient satisfaction process: Moving towards a comprehensive model. Med Care Rev 1993;50:219-48.

26. Cronin JJ, Brady MK, Hult GT. Assessing the effects of quality, value, and customer satisfaction on consumer behavioral intentions in service environments. J Retail 2000;76:193-218.

27. Saraswati MS, Kristina SA, Zulkarnain AK. Perceived service quality and patient satisfaction at pharmacy department in Yogyakarta, Indonesia. Int J Pharm Pharm Sci 2017;10:42-5.

28. Javadi MH, Gol R. Service quality evaluation in general department of health insurance of Fars Province using a SERVQUAL model (case study: Shiraz). Interdis J Contem Res Bus 2011;3:118-25.

29. Johansson P, Oleni M, Fridlund B. Patient satisfaction with nursing care in the context of health care: A literature study. Scand J Car Sci 2002; 16:337-44.

30. Fallowfield L, Jenkins V. Communicating sad, bad, and difficult news in medicine. Lancet 2004;363:312-9.

31. Jackson JL, Chamberlin J, Kroenke K. Predictors of patient satisfaction. Soc Sci Med 2001;52:609-20.

32. Gadalean I, Cheptea M, Constantin I. Evaluation of patient satisfaction. Appl Med Inform 2011;29:41-7.

33. Lee SJ, Back AL, Block SD, Stewart SK. Enhancing physician-patient communication. ASH Educ Program Book 2002;2002:464-83.

34. Al-Rashed SA, Wright DJ, Roebuck N, Sunter W, Chrystyn H. The value of inpatient pharmaceutical counseling to elderly patients prior to discharge. Br J Clin Pharmacol 2002;54:657-64.

35. Rathert C, May DR, Williams ES. Beyond service quality:
The mediating role of patient safety perceptions in the patient experience-satisfaction relationship. Health Care Manage Rev 2011;36:359-68.

36. Kjoenniksen I, Lindbaek M, Granas AG. Patients' attitudes towards and experiences of generic drug substitution in Norway. Pharm World Sci 2006;28:284-9.

37. Singhal GL, Anita K, Arun N. Jan Aushadhi stores in India and quality of medicines therein. Int J Pharm Pharm Sci 2011;3:204-7.

38. Rao KD, Peters DH, Bandeen-Roche K. Towards patient-centered health services in India-A scale to measure patient perceptions of quality. Int J Qual Health Care 2006;18:414-21.

39. Wen MM, Aref H, Abozaid A, Kandil NH, Elsobky YH. Quality evaluation and survey of the essential need for drug information centers. Int J Pharm Pharm Sci 2016;8:137-43.

40. Edwards JR, Bagozzi RP. On the nature and direction of relationships between constructs and measures. Psychol Methods 2000;5:155-74.

41. Chin WW. The partial least squares approach to structural equation modeling. Mod Method Bus Res 1998;295:295-336.

42. Kock N. Using Warp PLS in e-collaboration studies: What if I have only one group and one condition. Int J e-Collaboration 2013;9:1-12.

43. Bentler PM. Comparative fit indexes in structural models. Psychol Bull 1990;107:238-46.

44. Anderson JC, Gerbing DW. Structural equation modeling in practice: A review and recommended a two-step approach. Psychol Bull 1988;103:411-23.

45. Hair JF, Black WC, Babin BJ, Anderson RE, Tatham RL. Multivariate Data Analysis. Upper Saddle River, NJ: Prentice Hall; 1998.

46. Kock N, Gaskins L. Simpson's paradox, moderation and the emergence of quadratic relationships in path models: An information systems illustration. Int J App Nonlinear Sci 2016;2:200-34.

47. Kock N, Moqbel M. A six-stage framework for evolutionary is research using path models: Conceptual development and a social networking illustration. J Sys Info Tech 2016;18:64-88

48. Wetzels M, Odekerken-Schröder G, Van Oppen C. Using PLS path modeling for assessing hierarchical construct models: Guidelines and empirical illustration. MIS Quarter 2009;33:177-95.

49. Fornell C, Larcker DF. Structural equation models with unobservable variables and measurement error: Algebra and statistics. J Market Res 1981;18:382-8.

50. Baron RM, Kenny DA. The moderator-mediator variable distinction in social psychological research: Conceptual, strategic, and statistical considerations. J Pers Soc Psychol 1986;51:1173-82.

51. Bitner MJ. Evaluating service encounters: The effects of physical surroundings and employee responses. J Market 1990;1:69-82.

52. Epstein RM. Making communication research matter: What do patients notice, what do patients want, and what do patients need? Patient Educ Couns 2006;60:272-8

53. Berwick DM. What 'patient-centered' should mean: Confessions of an extremist. Health Affairs 2009;28:555-65

54. Carter RE, Lonial SC, Raju PS. Impact of quality management on hospital performance: An empirical examination. Qual Manage J 2010;17:8-24

55. Newton PN, Green MD, Fernández FM. Impact of poor-quality medicines in the 'developing' World. Trends Pharmacol Sci 2010;31:99-101.

56. Nyanwura EM, Esena RK. Essential medicines availability and affordability: A case study of the top ten registered diseases in Builsa district of Ghana. Int J Sci Tech Res 2013;2:208-19.

57. van Mook WN, van Luijk SJ, O’Sullivan H, Wass V, Zwaveling JH, Schuwirth LW, et al. The concepts of professionalism and professional behavior: Conflicts in both definition and learning outcomes. Eur J Intern Med 2009;20:85-9.

58. Richmond VP, Smith RS Jr., Heisel AD, McCroskey JC. The association of physician socio-communicative style with physician credibility and patient satisfaction. Commun Res Rep 2002;19:207-15.

59. Wrench JS, Booth-Butterfield M. Increasing patient satisfaction, and compliance: An examination of physician humor orientation, compliance-gaining strategies, and perceived credibility. Commun Quarter 2003;51:482-503.

60. Paulsel ML, McCroskey JC, Richmond VP. Perceptions of health care professionals' credibility as a predictor of patients' satisfaction with their medical care and physician. Commun Res Rep 2006;23:69-76.

61. Mayun IG, Indrasari M, Kusdhany LS. Relationship between patient's satisfaction of removable denture wearers and oral health-related quality of life. Int J Appl Pharm 2017;9:150-4. 